\title{
Intrapericardial recombinant tissue plasminogen activator in purulent pericarditis- case series
}

\author{
Małgorzata Dybowska ${ }^{*}$ (D), Monika Szturmowicz ${ }^{1}$, Lucyna Opoka ${ }^{2}$, Piotr Rudziński ${ }^{3}$ and Witold Tomkowski ${ }^{1}$
}

\begin{abstract}
Background: Pericardial constriction is one of the complications of purulent pericarditis (PP). Most difficult to treat, which may develop both in early and in the late period of the disease, resulting in a very poor prognosis.

Case presentation: We present case series of 4 patients with purulent pericarditis, in whom direct intrapericardial administration of recombinant tissue plasminogen activator ( $r$-tPA) was used.

Management of PP requires a combined surgical and medical approach. The most important is complete drainage of the effusion by subxiphoid pericardiotomy connected with complementary use of broad-spectrum antibiotics. Despite the use of broad- spectrum antibiotics, in some patients a large volume of daily drainage is still present. Constrictive pericarditis as a complication of PP is observed in majority of patients.

Intrapericardial administration of fibrinolytic agents, although not strongly recommended, can improve efficacy of antibiotic treatment especially in patients with loculation fluid and can prevent the development of constrictive pericarditis.

r-tPA was applied at a dose of $20 \mathrm{mg}$ dissolved in $100 \mathrm{ml}$ of normal saline in a $100 \mathrm{ml}$ syringe, administered by a large pericardial drain (Pezzer drain) installed into the pericardial cavity during pericardioscopy. The tube was closed and reopened after $24 \mathrm{~h}$.

No serious complications, such as bleeding, allergy or hypotension, were noted.

Conclusion: We present case series of 4 patients with purulent pericarditis, in whom direct intrapericardial administration of recombinant tissue plasminogen activator (r-tPA), prevented the development of constrictive pericarditis, and increased efficacy of antibiotic treatment without any significant complications.
\end{abstract}

Keywords: Purulent pericarditis, Constrictive pericarditis, Subxiphoid pericardiotomy, Fibrinolysis

\section{Introduction}

Purulent pericarditis (PP) is a rare cause of pericardial disease, with the prevalence of less than $3 \%$, but with potentially life-threatening complication [1]. Most frequently PP develops in the course of bacterial infections of the head, neck or respiratory tract, especially in immunocompromised hosts [2-4]. The other risk factors are chest surgery or injuries [2-4].

\footnotetext{
* Correspondence: dybowska@mp.pl

'I Department of Lung Diseases, National Tuberculosis and Lung Diseases Research Institute, ul Plocka 26, 01-138 Warsaw, Poland

Full list of author information is available at the end of the article
}

The recommended treatment of PP is based on pericardial drainage and intravenous antibiotics administration [3].

Intrapericardial use of fibrinolytic agents such as Streptokinase (SK) or Urokinase (UK) is suggested in case of early signs of pericardial constriction, fibrin deposits and loculation of the fluid [3].

Despite proper multidirectional treatment, PP still has a $20-30 \%$ mortality rate [2]. In the early stage of the disease, mortality is caused by cardiac tamponade and/or septic shock [3-6]. Late mortality in the course of PP is combined with pericardial constriction [2]. Constrictive 
pericarditis is characterized by loss of elasticity of the pericardium due to progressive fibrosis and in some cases - calcification. Reduced flexibility of the pericardium causes the increase of heart filling pressures and finally heart failure. Pericardiectomy, which is the treatment of choice in the case of constrictive pericarditis, exposes the patient to the possibility of complications and is combined with a mortality rate of about 4 , 9-8\% [7, 8].

Clinical observations based on a small group of patients suggest that the intrapericardial administration of fibrinolytic drugs, although not strongly recommended, is an effective way to prevent the development of pericardial constriction and thus protects the patient from a pericardiectomy $[2,3]$. Up to now, no randomized studies, confirming the efficacy of such treatment, have been performed.

We present 4 patients with purulent pericarditis, successfully treated with intrapericardial administration of recombinant tissue plasminogen activator.

\section{Case presentation}

The clinical data of 4 patients with confirmed PP, who were treated with intrapericardial recombinant tissue plasminogen activator ( $\mathrm{r}-\mathrm{tPA})$ is presented in Table 1 . The group of patients consists of 3 males and 1 female, age 27 to 69 years.

PP was recognized in the patients who were suffering from generalized weakness, dyspnoea, fever, chest pain and - in one case- septic shock. Pericardial effusion (hyperechogenic fluid around the whole heart and in some cases with a large amount of fibrin) was diagnosed by echocardiography. The purulent character of the fluid was confirmed by physical and biochemical examination (turbid characteristics, low glucose level, high LDH and high WBC count with an increased number of neutrophils).

In one patient purulent pericarditis developed in the course of bacterial knee -joint inflammation, in another, diagnosed with common variable immunodeficiency, in the course of pneumonia and empyema. In the remaining two patients, the cause of pericardial infection has not been identified.

The purulent pericardial fluid was obtained from all of the patients, the cultures of the fluid tested positive for MSSA in one patient and for S. epidermidis in another. Because of the fact that S.epidermidis was diagnosed in two different fluid cultures, it was considered a cause of purulent pericarditis and not a contamination. In the other two patients, the cultures of pericardial fluid were negative, probably due to previous antibiotic therapy.

Subxiphoid pericardiotomy under general anesthesia has been performed in all of the patients with implantation of a large tube drain (Pezzer drain). The indications for intrapericardial fibrinolytic treatment (IFT) were: prolonged purulent drainage and fibrin deposits in pericardium (4 patients), early echocardiographic signs of pericardial constriction despite optimal treatment (3 patients), excessive pericardial drainage with signs of pericardial fluid inoculation (1 patient- case 4). Early echocardiographic signs of constriction were defined as: thickening of pericardium, the mitral inflow velocities showing a pseudo-normal or restrictive filling pattern (E/A $>1$ and deceleration time $<150 \mathrm{~ms}$ ), the respiratory variation in filling velocities, inferior vena cava plethora with expiratory hepatic vein diastolic reversal wave.

$\mathrm{r}$-tPA was applied at a dose of $20 \mathrm{mg}$ dissolved in 100 $\mathrm{ml}$ of normal saline in a $100 \mathrm{ml}$ syringe, administered by a large pericardial drain (Pezzer drain). The tube was closed and re-opened after $24 \mathrm{~h}$.

Two patients received a the single dose of $\mathrm{r}$-tPA, and the remaining two - two doses.

In one case (case 2) it was related to an extensive leak of pericardial fluid next to the drain, and the necessity of early opening of the drain, in another one (case 4) with the persistence of a large amount of fibrin in the pericardium with fluid loculations. The repeated intrapericardial fibrinolysis in this patients was caused by excessive pericardial drainage.

The treatment has been effective in all of the patients, diminishing the echocardiographic signs of early constriction in 3 patients, and reducing large pericardial drainage in the remaining one. The drains were removed 6-8 days after the last dose of $r$-tPA.

The decision to remove the drain from the pericardium was made based on the reduction of daily drainage to less than $20 \mathrm{ml}$, and echocardiographic signs of remission (fluid withdrawal and regression of early constriction features).

In each of these four cases, the successful treatment of purulent pericarditis was achieved.

Chest computed tomography scans before and after intrapericardial r-tPA therapy in the patient with purulent pericarditis in the course of pneumonia and empyema due to common variable immunodeficiency syndrome were presented in Figs. 1a-b and 2.

An MRI was not performed due to the lack of availability and long duration of the study -two patients were in severe condition, one was in septic shock.

Additionally MRI is not listed in 2015 guidelines as a first line diagnostic method for patients with PP.

It is a valuable procedure to confirm constrictive pericarditis for stable patients, before surgerypericardiectomy. All cases were monitored by bedside echocardiography every day.

No serious complications, such as bleeding, allergy or hypotension, were noted. In one case, due to extensive leak of pericardial fluid next to the drain, it was reopened after $5 \mathrm{~h}$. 


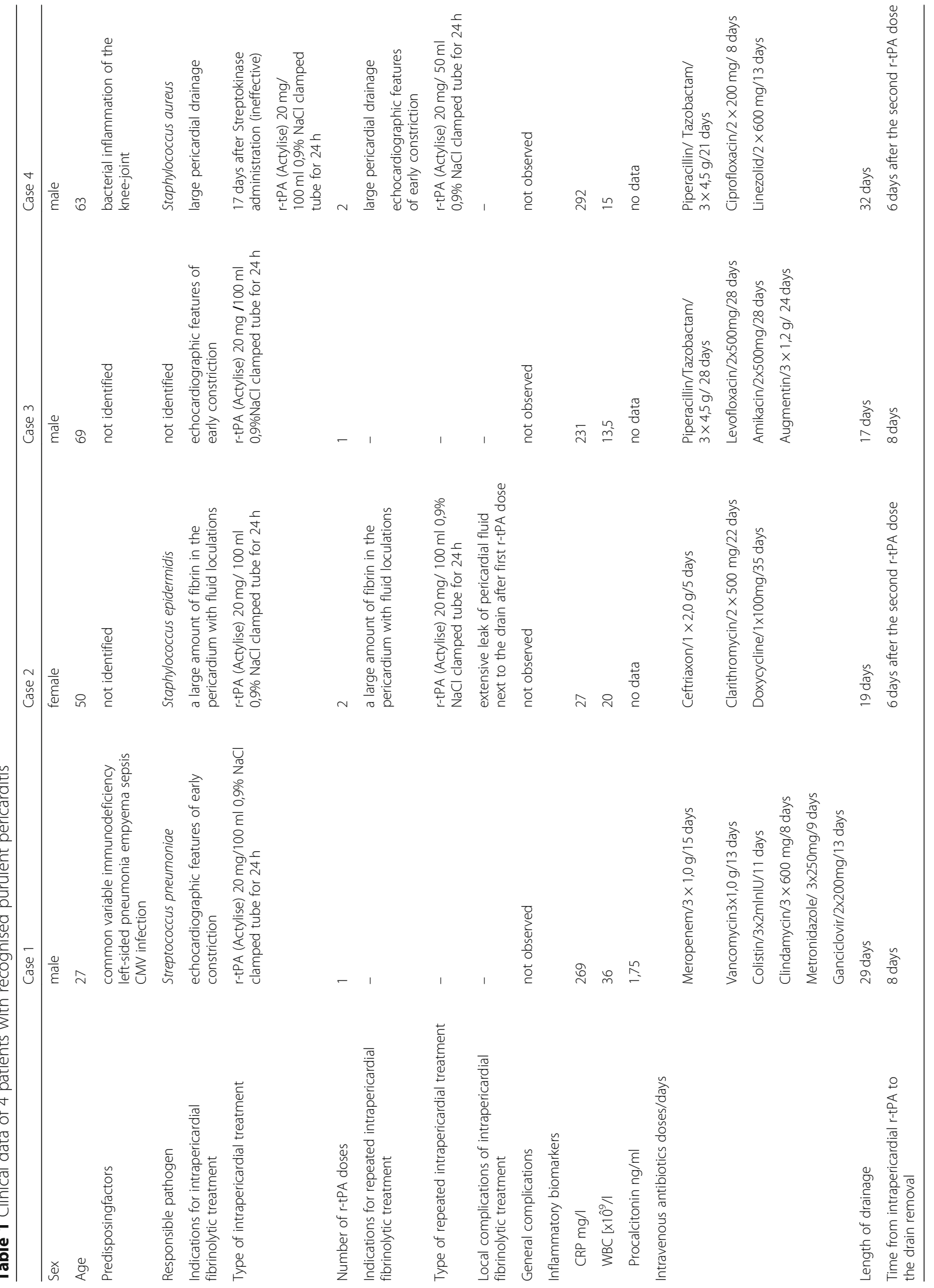



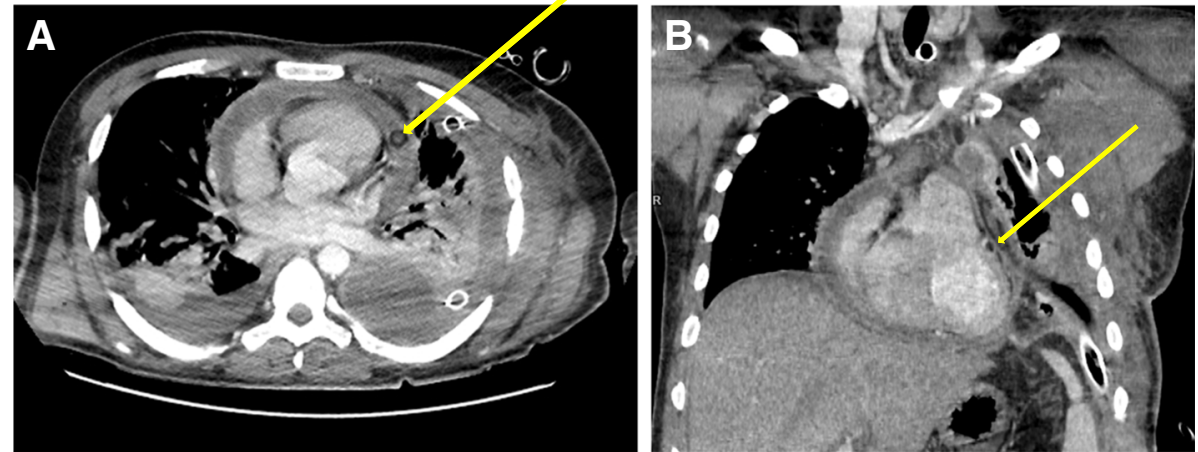

Fig. 1 Chest CT performed before intrapericardial r-tPA treatment. Purulent pericarditis and pleuritis in the course of common variable immunodeficiency syndrome. Pericardial effusion, the layer of $17 \mathrm{~mm}$. Thickening of the pericardium up to $4 \mathrm{~mm}$. Drain in the pericardial sac arrow. Bilateral pleural effusion, drain in the left pleura. Large atelectasis in the lower parts of the lungs due to pleural effusion. $\mathbf{a}$ - Mediastinal window, axial view. $\mathbf{b}$ - Mediastinal window, frontal view

An appropriate, broad-spectrum antibiotic therapy was used intravenously, on average - for 21 days.

In all of the patients- intrapericardial administration of fibrinolytic agents, caused remission of early sings of pericardial constriction, and regression of pericardial effusion.

The patients were observed for 10 months (case 1), 13 months (case 2), 30 months (case 3 ) and 7 years (case 4) respectively. The repeated echocardiographic examinations revealed no signs of pericardial constriction, at follow -ups.

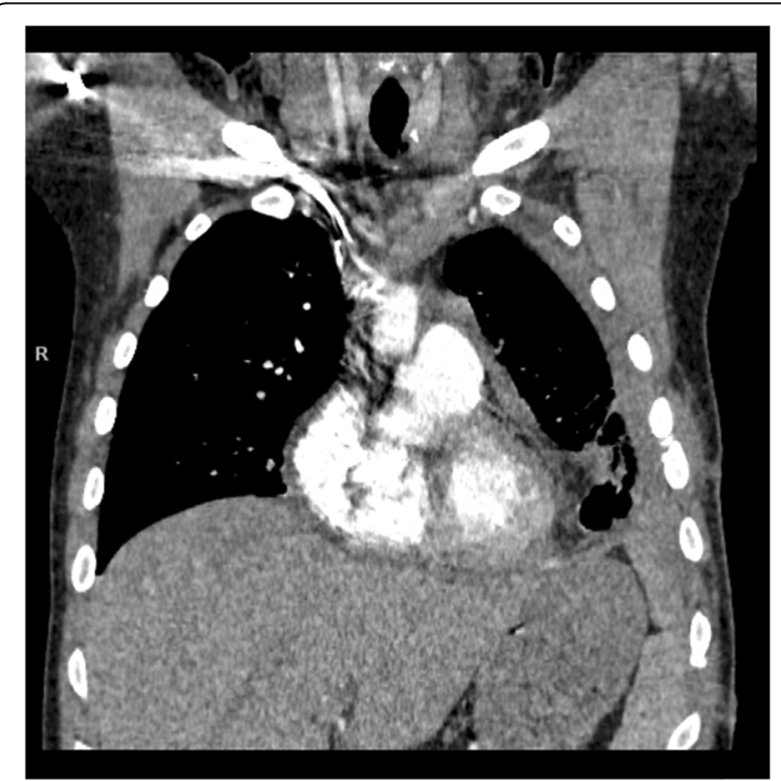

Fig. 2 Chest CT performed 27 days after intrapericardial r-tPA treatment (mediastinal window, frontal view). Pericardial effusion, the layer of $5 \mathrm{~mm}$, normal thickness of pericardium. Left sided pleural effusion with inoculations

\section{Discussion and conclusions}

We presented 4 cases of purulent pericarditis, treated successfully with intrapericardial $r$-tPA.

Management of PP requires a combined surgical and medical approach. The most important is complete drainage of the effusion combined with complementary use of broad-spectrum antibiotics. Because of loculations and adhesions simple evacuation by surgical or percutaneous drainage may not prevent constrictive pericarditis [9]. Open surgical drainage through subxiphoid pericardiotomy is preferable [5]. Pericardiostomy decreased mortality to about $50 \%$, and a further decrease of mortality to $30 \%$ has been associated with intravenously antibiotics use.

The guidelines of the European Society of Cardiology from both 2004 and 2015 recommend intrapericardial use of fibrinolytic agents in the therapy of PP, however the class of recommendations is low (IIa) as well as the level of scientific evidence $(C)[3,5]$. Moreover, the optimal type of fibrinolytic agent, dose, method of administration, the volume of the infused solution, used in direct, pericardial treatment are still not known $[3,5]$.

As PP is a rare entity, the randomized clinical trials are lacking and all the information concerning treatment efficacy and safety comes from case reports or case series.

The clinical experience with IFT has been summarized by Augustin et al. in 2011 [2] and recently by Wiyeh et al. [4]. Majority of the patients have been treated with intrapericardial streptokinase (SK) $[2,4]$.

Long term effect has been achieved in $86-89 \%$ of patients $[2,4]$. Several non-fatal complications have been noted: one case of cardiac tamponade due to bleeding, several cases of minor bleeding and occasionally hypotension, febrile reaction, and fistula formation [2, 4]. Because of the risk of allergy and immunization, using UK or r-tPA has been suggested [10]. 
Our own experience with SK used as IFT, concerns 4 cases, in one of them severe intrapericardial bleeding occurred as a complication, and in one case the therapy was ineffective and the patient received $r$-tPA as second line treatment (case 4) [11, 12]. Major haemorrhage due to instillation of SK were also reported by other authors [2]. One case of haemorrhagic tamponade after SK fibrinolysis was described in a child [13].

In comparison to the above mentioned data from the literature $[2,4]$, the efficacy of intrapericardial r-tPA, reported in the present case series was non-inferior to SK. Nevertheless it is difficult to compare these data, due to a small number of patients, as well as different indications for IFT. Our indications consisted mainly of signs of early constriction, whereas other authors used IFT in case of drainage ineffectiveness with signs of cardiac tamponade in the course of PP.

The safety of intrapericardial r-tPA was high, no complications have been observed in our patients, apart from a pericardial leak in one case probably due to the large volume of purulent fluid released from loculations.

Use of r-tPA allows subsequent administration of the same drug (case 2 and case 4 were treated with repeated intrapericardial dose of r-tPA without any complications after second administration), because of no immunization.

Another important aspect concerns the timing of IFT in case of early constriction. As fibrin formation occurs during the first week of PP, fibrinolytic therapy should be used early, preferably in the first two weeks of the disease, however there in no consensus on the appropriate timing of fibrinolysis [2]. It should be pointed out that pericardiectomy is recognized as a surgical technique that provides significant improvement and survival, but is combined with high mortality [8].

Use of r-tPA significantly decreased signs of constrictive pericarditis and decreased necessity of surgical treatment in cases with PP [11].

Moreover, in the literature, there is no consensus on what dose and how intrapericardial fibrinolysis should be administered.

The limited data available which is based on individual case reports present a range of doses from $2 \mathrm{mg} / 10 \mathrm{ml}$ or $30 \mathrm{mg}$ in 1 dose [2].

Moreover, limited data concerning r-tPA dose for the treatment of empyema suggested a dose of $10 \mathrm{mg}[14,15]$.

In our schema, based on the 4 cases, we proposed 20 $\mathrm{mg}$ r-tPA diluted in $100 \mathrm{ml}$ normal saline and clamping the drain for $24 \mathrm{~h}$.

Without prejudice to the efficacy and safety of direct, intrapericardial administration of fibrinolytic agents in cases with confirmed PP, we would like to recommend, the described above schema consisting of $20 \mathrm{mg}$ of r-tPA dissolved in $100 \mathrm{ml}$ of saline in patients with previously performed subxiphoid pericardiostomy followed by insertion of the large drain connected with broadspectrum antibiotics. We have included our recommendations in algorithm. Such therapy seems to be safe and effective in case of early pericardial constriction in the course of PP.

\section{Supplementary information}

Supplementary information accompanies this paper at https://doi.org/10. 1186/s12872-020-01674-z.

Additional file 1. Algorithm.

\section{Abbreviations}

PP: Purulent pericarditis; r-tPA: Recombinant tissue plasminogen activator; IFT: The indications for intrapericardial fibrinolytic treatment;

SK: Streptokinase; UK: Urokinase

\section{Acknowledgements}

Not applicable.

\section{Authors' contributions}

M.D. analyzed and interpreted the patient data, has drafted the work, corresponding author. M.Sz. analyzed and interpreted the patient data. L.O. radiologist, interpreted $C T$ scans, analyzed and interpreted the patient data. P.R. surgeon, performed pericardioscopy, analyzed and interpreted the patient data. W.T. study coordinator, general supervision of the research, had substantially modified version and substantively revised work. All authors read and approved the final manuscript

Funding

Not applicable.

Availability of data and materials

Available from the authors in source materials and clinical data at the National Tuberculosis and Lung Diseases Research Institute, Plocka 26, $01-$ 138 Warsaw Poland

Ethics approval and consent to participate

Not applicable.

Consent for publication

Written informed consent was obtained from all patient for publication of this Case Report and any accompanying images and videos. A copy of the written consent is available for review by the Editor of this journal.

\section{Competing interests}

Not applicable.

\section{Author details}

${ }^{1}$ I Department of Lung Diseases, National Tuberculosis and Lung Diseases Research Institute, ul Plocka 26, 01-138 Warsaw, Poland. ²Department of Radiology, National Tuberculosis and Lung Diseases Research Institute, Plocka 26, 01-138 Warsaw, Poland. ${ }^{3}$ Department of Thoracic Surgery, National Tuberculosis and Lung Diseases Research Institute, Plocka 26, 01-138 Warsaw, Poland.

Received: 20 April 2020 Accepted: 19 August 2020

Published online: 27 August 2020

\section{References}

1. Imazio M. Noninfectious pericarditis: management challenges for cardiologists. Kardiol Pol. 2020;78(5):396-403. https://doi.org/10.33963/KP. 15353.

2. Augustin $P$, Desmard M, Mordant $P$, et al. Clinical review: Intrapericardial fibrinolysis in management of purulent pericarditis. Crit Care. 2011;15:220. 
3. Adler Y, Charron P, Imazio M, et al. ESC scientific document group. 2015 ESC guidelines for the diagnosis and management of pericardial diseases: the task force for the diagnosis and Management of Pericardial Diseases of the European Society of Cardiology (ESC)endorsed by: the European Association for Cardio-Thoracic Surgery (EACTS). Eur Heart J. 2015;36:292164. https://doi.org/10.1093/eurheartj/ehv318.

4. Wiyeh A, Ochodo E, Wiysonge $C$, et al. A systematic review of the efficacy and safety of intrapericardial fibrinolysis in patients with pericardial effusion. Int J Cardiol. 2018;250:223-8.

5. Maisch B, Seferović PM, Ristić AD, et al. Guidelines on the diagnosis and management of pericardial diseases executive summary; the task force on the diagnosis and management of pericardial diseases of the European society of cardiology. Eur Heart J. 2004;25:587-610.

6. Ristic A, Imazio M, Adler $Y$, et al. Triage strategy for urgent management of cardiac tamponade: a position statement of the European Society of Cardiology Working Group on myocardial and pericardial diseases. Eur Heart J. 2014:35:2279-84

7. Chowdhury UK, Subramaniam GK, Kumar AS, et al. Pericardiectomy for constrictive pericarditis: a clinical, echocardiographic, and hemodynamic evaluation of two surgical techniques. Ann Thorac Surg. 2006;81:522-9.

8. Gatti G, Fiore A, Ternacle J, et al. Pericardiectomy for constrictive pericarditis: a risk factor analysis for early and late failure. Heart Vessel. 2020;35(1):92103. https://doi.org/10.1007/s00380-019-01464-4.

9. Sethi GK, Nelson RM, Jenson CB. Surgical Management of Acute Septic Pericarditis. Chest. 1973;63(5):732-5. https://doi.org/10.1378/chest.63.5.732.

10. Tsang TS, Califf RM, Stebbins AL, et al. Incidence and impact on outcome of streptokinase allergy in the GUSTO-I trial. Am J Cardiol. 1997;79:1232-5.

11. Dybowska M, Kazanecka B, Kuca P, et al. Intrapericardial fibrinolysis in purulent pericarditis - case report. Int J Emerg Med. 2015;8:36.

12. Tomkowski WZ, Gralec R, Kuca P, Burakowski J, Orłowski T, Kurzyna M. Effectiveness of intrapericardial administration of streptokinase in purulent pericarditis. HERZ. 2004;29:802-5.

13. Juneja R, Kothari SS, Saxena A, et al. Intrapericardial streptokinase in purulent pericarditis. Arch Dis Child. 1999;80:275-7.

14. Light RW. Parapneumonic effusions and empyema. Proc Am Thorac Soc. 2006;:3:75-80.

15. Bédat B, Plojoux J, Noel J, et al. Comparison of intrapleural use of urokinase and tissue plasminogen activator/DNAse in pleural infection. ERJ Open Res. 2019:5(3):00084-2019. https://doi.org/10.1183/23120541.00084-2019.

\section{Publisher's Note}

Springer Nature remains neutral with regard to jurisdictional claims in published maps and institutional affiliations.

Ready to submit your research? Choose BMC and benefit from:

- fast, convenient online submission

- thorough peer review by experienced researchers in your field

- rapid publication on acceptance

- support for research data, including large and complex data types

- gold Open Access which fosters wider collaboration and increased citations

- maximum visibility for your research: over $100 \mathrm{M}$ website views per year

At $\mathrm{BMC}$, research is always in progress.

Learn more biomedcentral.com/submissions 